\title{
Reduction in the Emissions and Toxicity of Polycyclic Aromatic Hydrocarbons from a Heavy-duty Diesel Engine with the Latest Aftertreatment Devices
}

\author{
Keiko Shibata, ${ }^{*}, a, b$ Nobuhiro Yanagisawa, ${ }^{a}$ Yoshihisa Tashiro, ${ }^{a}$ Takayuki Mukunashi, ${ }^{c}$ \\ Takao Onodera, ${ }^{c}$ and Kazuhiko Sakamoto ${ }^{b, d}$
}

${ }^{a}$ Isuzu Advanced Engineering Center, Ltd., 8 Tsuchidana, Fujisawa, Kanagawa 252-8501, Japan, ${ }^{b}$ Department of Environmental Science and Technology, Graduate School of Science and Engineering, Saitama University, 255 Shimo-Ohkubo, Sakura, Saitama 3388570, Japan, ' Isuzu Moters Limited, 8 Tsuchidana, Fujisawa, Kanagawa 252-8501, Japan, and ${ }^{d}$ Institute for Environmental Science and Technology, Saitama University, 255 Shimo-Okubo, Sakura-ku, Saitama, Saitama 338-8570, Japan

(Received July 2, 2009; Accepted October 16, 2009; Published online October 21, 2009)

\begin{abstract}
Polycyclic aromatic hydrocarbons (PAHs) bound in particles from automobile emissions may cause adverse human health. In this study, a 3L heavy-duty diesel engine with and without the latest aftertreatment devices were characterized for PAH emissions and toxicity using European Transient Cycle (ETC) and the European Stationary Cycle (ESC). The latest combination of aftertreatment devices including a diesel oxidation catalyst (DOC) and a catalyzed diesel particulate filter (c-DPF) were used to remove diesel exhaust particles (DEP). Particle size distribution and number concentrations were measured using a TSI Engine Exhaust Particle Sizer. Eight PAHs [benz $(a)$ anthracene, chrysene, benzo $(b)$ fluoranthene, benzo $(k)$ fluoranthene, benzo $(a)$ pyrene, indeno(1,2,3$c d)$ pyrene, dibenz $(a, h)$ anthracene, and benzo( $g h i)$ perylene] within the DEP were analyzed by thermal desorptiongas chromatography/mass spectrometry (TD-GC/MS). Elemental carbon (EC) and organic carbon (OC) were also analyzed with a thermal/optical carbon analyzer. The results indicated that 4-ring PAH emissions are larger than 5 or 6-ring PAH emissions, with and without the aftertreatment devices in place. Number concentrations of particles, PAHs and EC mass emissions in diesel exhaust were dramatically decreased by the aftertreatment devices: > 99\%, $>97 \%$ and $>99 \%$, respectively. To evaluate the toxicity of PAHs in the DEP, we calculated benzo(a)pyrene equivalent (BaPeq) emissions using a toxic equivalency factor (TEF). Total $\mathrm{B} a$ Peq emissions of eight PAHs were also substantially decreased by the aftertreatment devices (> 95\%). However, the decrease rate of OC was lower than EC $(>72 \%)$. We demonstrated that number concentrations of DEP, PAH emissions, EC and BaPeq emissions were similarly and substantially decreased by the latest aftertreatment devices.
\end{abstract}

Key words — polycyclic aromatic hydrocarbon, diesel exhaust particles, toxicity, toxic equivalency factor

\section{INTRODUCTION}

Polycyclic aromatic hydrocarbons (PAHs) are generated during incomplete combustion such as wood burning, cooking and road traffic. The composition of the PAH emissions is dependent on a variety of factors, for example, the fuel and its properties, and the combustion technology. ${ }^{1)}$ PAHs bound in nano and ultrafine particles from automobiles may cause adverse health effects. ${ }^{2}{ }^{2}$ Some PAHs are known to be mutagenic and carcinogenic. ${ }^{3,4)}$ Therefore, $\mathrm{PAH}$ emissions from automobiles require anal-

\footnotetext{
*To whom correspondence should be addressed: Isuzu Advanced Engineering Center, Ltd., 8 Tsuchidana, Fujisawa, Kanagawa 252-8501, Japan. Tel.: +81-46-645-2614; Fax: +81-46-645-2405; E-mail: keiko@iaec.isuzu.co.jp
}

ysis.

In recent years, diesel exhaust particles (DEP) have been reduced to levels close to atmospheric pollution levels by various diesel aftertreatment devices. We used the combination of a diesel oxidation catalyst (DOC) and a catalyzed diesel particulate filter (c-DPF) as the latest aftertreatment devices in this study.

The thermal desorption-gas chromatography/mass spectrometry (TD-GC/MS) method is suitable for the analysis of low mass levels of organic compounds, such as PAHs, $n$-alkanes, and $n$-monocarboxylic acids in atmospheric aerosols. $^{5-13)}$ This method does not require an organic solvent extraction process, uses direct sample injection and is highly sensitive. 
Table 1. Specifications of Test Engine, Fuel, Oil and Aftertreatment Devices

\begin{tabular}{|c|c|c|}
\hline \multirow[t]{7}{*}{ Engine } & $\overline{\text { Type }}$ & ISUZU DI TCI Diesel \\
\hline & Cylinder number & 4 \\
\hline & Displacement (1) & 2.999 \\
\hline & Max power (kW @ rpm) & $110 @ 2800$ \\
\hline & Max torque (N·m @ rpm) & $375 @ 1600$ \\
\hline & Injection system & Common rail \\
\hline & Air charging system & Inter-cooled turbocharger \\
\hline \multirow[t]{5}{*}{ Fuel } & Type & JIS 2 \\
\hline & Cetane index & 56.5 \\
\hline & Sulfur content (ppm) & 5 \\
\hline & Density $\left(\mathrm{g} / \mathrm{cm}^{3}\right) @ 15^{\circ} \mathrm{C}$ & 0.8313 \\
\hline & Viscosity $\left(\mathrm{mm}^{2} / \mathrm{s}\right) @ 30^{\circ} \mathrm{C}$ & 3.633 \\
\hline Oil & SAE grade & $10 \mathrm{~W}-30$ \\
\hline $\begin{array}{l}\text { Aftertreatment } \\
\text { system (DOC) }\end{array}$ & Material and type & $\begin{array}{l}\text { Diesel oxidation catalyst } \\
\text { (Precious metal, Pt group) }\end{array}$ \\
\hline $\begin{array}{l}\text { Aftertreatment } \\
\text { system (c-DPF) }\end{array}$ & Material and type & $\begin{array}{l}\text { Cordierite, Wall-flow, Catalyzed } \\
\text { (Precious metal, Pt group) }\end{array}$ \\
\hline
\end{tabular}

In this study, we used this method to analyze eight PAHs in a small amount of DEP that were collected from a diesel engine fitted with aftertreatment devices. We optimized the conditions for TD-GC/MS combined with a cryogenic-focus trap, selected-ion monitoring (SIM), and a deuterated internal standard for more sensitive analysis and good separation.

Size distributions and number concentrations of DEP were measured in the size range of 5.6-560 nm using an Engine Exhaust Particle Sizer (EEPS). Elemental carbon (EC) and organic carbon (OC) in the DEP were also analyzed with a thermal/optical carbon analyzer according to the IMPROVE protocol. $^{14)}$

In addition, we estimated toxicity of the eight PAHs using a toxic equivalency factor (TEF). ${ }^{15}$ ) These values have been used as a way of comparing the carcinogenic potency of the individual PAHs with the carcinogenicity of benzo $(a)$ pyrene $(\mathrm{B} a \mathrm{P})$ and were expressed in terms of $\mathrm{B} a \mathrm{P}$ equivalents (BaPeq). ${ }^{15)}$ We calculated $\mathrm{B} a$ Peq emissions with and without DOC $+\mathrm{c}-\mathrm{DPF}$, and evaluated the reduction in their toxicity in the presence of the aftertreatment devices.

We evaluated the distribution of the number concentration of DEP, PAH emissions, EC, OC and $\mathrm{B} a$ Peq emissions, with and without the latest aftertreatment devices.

\section{MATERIALS AND METHODS}

Engine Specifications and Test Cycles — The specifications of the test engine, fuel, oil, and aftertreatment devices are shown in Table 1. To suit Euro V Regulations, DOC and c-DPF were needed, which are the latest combination in aftertreatment devices for diesel engines. The DOC catalyzed the oxidation of CO and hydrocarbons. The c-DPF is a filter coated with a precious metal catalyst that serves as an active regeneration system. The regeneration frequency of this device changes depending on how it is used, but automatic regeneration occurs generally around every $300 \mathrm{~km}$. However, all experiments were carried out without regeneration occurring in the aftertreatment devices.

A heavy-duty diesel engine with and without DOC + c-DPF was operated for $1800 \mathrm{~s}$ for the European Transient Cycle (ETC) and the European Stationary Cycle (ESC). The engine was supplied with the aftertreatment devices already fitted, but these were removed before starting the experiments of without the aftertreatment devices condition. The experiments were carried out with this engine on an engine dynamometer. The loads (\%) and speeds (\%) of both test cycles are shown in Fig. 1.

The ETC is a transient cycle that covers three parts of urban, rural, and highway driving for the emission certification of heavy-duty diesel engines in Europe. The duration of each part is $600 \mathrm{~s}$. The duration of the entire cycle is $1800 \mathrm{~s}$, with and without the aftertreatment devices. The ESC is steadystate cycle for emission certification of heavy-duty 
ETC

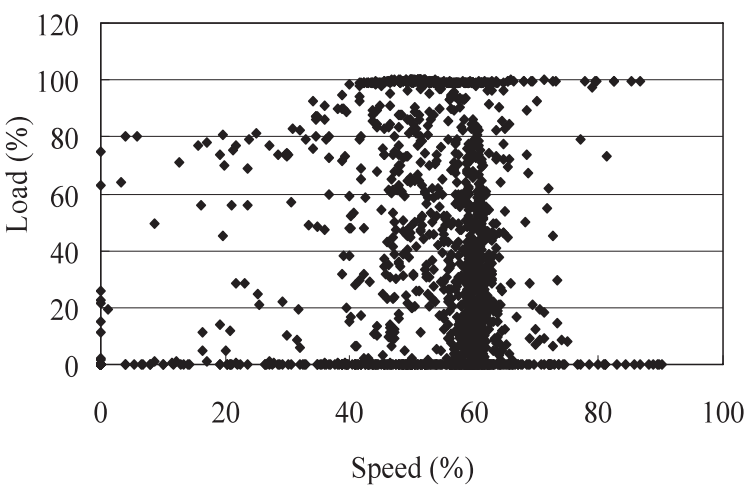

ESC

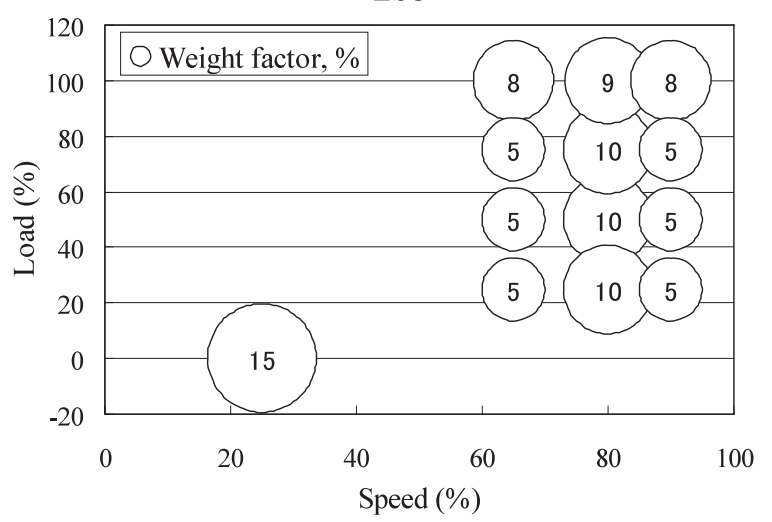

ETC

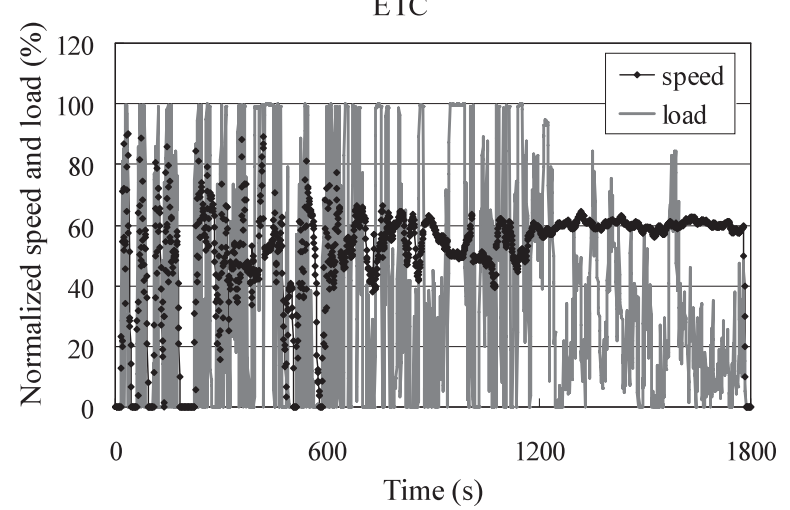

Fig. 1. Loads (\%) and Speeds (\%) of the Test Cycles, ETC and ESC

diesel engines in Europe, and the engine is operated over a sequence of 13 modes. The engine must be operated for the prescribed time in each mode. The load and speed changes were completed in the first $20 \mathrm{~s}$. The duration of the entire cycle is $1800 \mathrm{~s}$ as well as ETC, with and without the aftertreatment devices. Emissions were measured during each mode and averaged over the cycle using a set of weight factors. As a whole, the load (\%) for the ESC is higher than the ETC, as shown in Fig. 1.
Table 2. Physical Properties and the LOD and the LOQ of PAHs

\begin{tabular}{lcccc}
\hline \hline PAH & M.W. ${ }^{a)}$ & B.P. $\left({ }^{\circ} \mathrm{C}\right)^{a)}$ & LOD $^{b)}$ & LOQ $^{c)}$ \\
\hline $\mathrm{B} a \mathrm{~A}$ & 228.3 & 437.6 & 0.004 & 0.014 \\
$\mathrm{CHR}$ & 228.3 & 448 & 0.002 & 0.009 \\
$\mathrm{~B} b \mathrm{~F}$ & 252.3 & 357 & 0.003 & 0.011 \\
$\mathrm{~B} k \mathrm{~F}$ & 252.3 & 480 & 0.002 & 0.008 \\
$\mathrm{~B} a \mathrm{P}$ & 252.3 & 495 & 0.005 & 0.017 \\
$\mathrm{I} c d \mathrm{P}$ & 276.3 & 536 & 0.066 & 0.219 \\
$\mathrm{D} a h \mathrm{~A}$ & 278.3 & 524 & 0.167 & 0.557 \\
$\mathrm{~B} g h i \mathrm{P}$ & 276.3 & 500 & 0.035 & 0.116 \\
\hline
\end{tabular}

M.W., molecular weight. B.P., boiling point. $a$ ) Values reported by Ho and Yu (2004). ${ }^{9)}$ b) LOD is defined as $3 \sigma$ of the peak area ratio of each PAH versus the internal-standard of the lowest concentration of the calibration curve $(n=30) . c$ ) LOQ is defined as $10 \sigma$ of the peak area ratio of each PAH versus the internal-standard of the lowest concentration of the calibration curve $(n=30)$.

Reference Material — For quantification of the PAHs, standard reference material (SRM) 1647e solution was purchased from the National Institute of Standards and Technology (NIST, Gaithersburg, MD, U.S.A.). SRM 1647e solution contains 16 PAHs in acetonitrile. We chose eight PAHs as target compounds that have four, five, or six aromatic rings and molecular weights $>220$ and are difficult to volatize from quartz-fiber filters. The eight PAHs were benz $(a)$ anthracene $(\mathrm{B} a \mathrm{~A})$, chrysene $(\mathrm{CHR})$, benzo $(b)$ fluoranthene $(\mathrm{B} b \mathrm{~F})$, benzo $(k)$ fluoranthene $(\mathrm{B} k \mathrm{~F}), \quad$ benzo $(a)$ pyrene $\quad(\mathrm{B} a \mathrm{P}), \quad$ indeno(1,2,3$c d)$ pyrene $(\mathrm{I} c d \mathrm{P}), \operatorname{dibenz}(a, h)$ anthracene $(\mathrm{D} a h \mathrm{~A})$, and benzo $($ ghi $)$ perylene $(\mathrm{B} g h i \mathrm{P})$. The physical properties, limit of detection (LOD) and limit of quantification (LOQ) of each PAH are shown in Table 2. We diluted with HPLC-grade acetonitrile to prepare calibration curves. The certified concentration of $\mathrm{B} a \mathrm{~A}$ in $1647 \mathrm{e}$ solution is $4.09 \pm 0.09 \mathrm{mg} / \mathrm{l}$, $\mathrm{CHR}$ is $3.60 \pm 0.08 \mathrm{mg} / \mathrm{l}, \mathrm{B} b \mathrm{~F}$ is $4.19 \pm 0.09 \mathrm{mg} / \mathrm{l}$, $\mathrm{B} k \mathrm{~F}$ is $4.69 \pm 0.10 \mathrm{mg} / \mathrm{l}, \mathrm{B} a \mathrm{P}$ is $4.87 \pm 0.12 \mathrm{mg} / \mathrm{l}$, $\mathrm{I} c d \mathrm{P}$ is $4.27 \pm 0.13 \mathrm{mg} / \mathrm{l}, \mathrm{D} a h \mathrm{~A}$ is $3.49 \pm 0.20 \mathrm{mg} / \mathrm{l}$, $\mathrm{B}$ ghiP is $3.67 \pm 0.13 \mathrm{mg} / \mathrm{l}$. However we did not confirm the linearity of the calibration curve and net recoveries of the other eight PAHs (naphthalene, acenaphthylene, acenaphthene, fluorene, phenanthrene, anthracene, fluoranthene, and pyrene) in SRM 1647e solution because they may vaporize during the spiking process.

CHR- $d_{12}$ solution in dichloromethane was purchased from Supelco (Bellefonte, PA, U.S.A.) for use as an internal standard. CHR- $d_{12}$ solution was selected because its analytical behavior is similar to that of the target compounds. ${ }^{16)}$ To pre- 
pare a calibration curve, we spiked diluted standard solution of SRM 1647e on quartz-fiber filters with a microsyringe and added $2 \mu \mathrm{l}$ of CHR$d_{12}$ solution diluted $10000: 1$ with dichloromethane $(0.4 \mathrm{ng})$. The calibration curve was obtained from the area ratio $\mathrm{PAH} / \mathrm{CHR}-d_{12}$ and the concentration ratio $\mathrm{PAH} / \mathrm{CHR}-d_{12}$.

Number Concentrations of DEP — The number concentrations of DEP emitted from the engine under the test conditions were measured, with and without the aftertreatment devices, using an EEPS Model 3090 (TSI Inc., Shoreview, MN, U.S.A.). This instrument, which uses electrical mobility technology, measures the size distribution of engine exhaust particles with diameters from 5.6 to $560 \mathrm{~nm}$ and has a fast time resolution. It displays measurements in 32 channels (16 channels per decade) and operates at ambient pressure to prevent evaporation of volatile and semi-volatile particles. In this study, the dilution ratio was held constant at $15: 1$. This experiment was separated from the sampling experiment because the dilution conditions were different.

Filter Sampling —— We used HORIBA micro tunnel as a partial flow dilution system ${ }^{17,18)}$ to dilute and cool the exhaust during sampling; the flow rate was set to $801 / \mathrm{min}$. The exhaust division ratio of the partial flow dilution tunnel was held constant at 600.

DEP are usually collected on a Teflonimpregnated glass fiber filter, but we selected quartz-fiber filters (2500QAT-UP, Pallflex Products Corp., NY, U.S.A.) because of thermal desorption and carbon analysis. Quartz-fiber filters were conditioned by baking for $2 \mathrm{hr}$ in an electric furnace at $700^{\circ} \mathrm{C}$ before their initial weighing. In this study, sampling time was the same under all experiments. DEP were collected on a 60-mm-diameter area of a 70-mm-diameter filter. The filters were weighed before and after collection of DEP by means of a microbalance (readability $1 \mu \mathrm{g}, \mathrm{M} 3 \mathrm{P}-\mathrm{F}$, Sartorius AG, Goettingen, Germany) in a chamber in which the temperature and relative humidity were controlled at $25 \pm 5^{\circ} \mathrm{C}$ and $50 \pm 5 \%$, respectively. After sampling, the filters were stored at $-80 \pm 2^{\circ} \mathrm{C}$ until analysis. Before analysis, an area with a diameter of $10 \mathrm{~mm}$ was punched from the filter, and an internal standard solution $(2 \mu \mathrm{l}$ of a $0.2 \mathrm{ng} / \mu \mathrm{l})$ was added. The filters were dried under helium gas for about $1.5 \mathrm{~min}$ prior to TD-GC/MS analysis. Each filter sample was set into the middle of a TD tube.

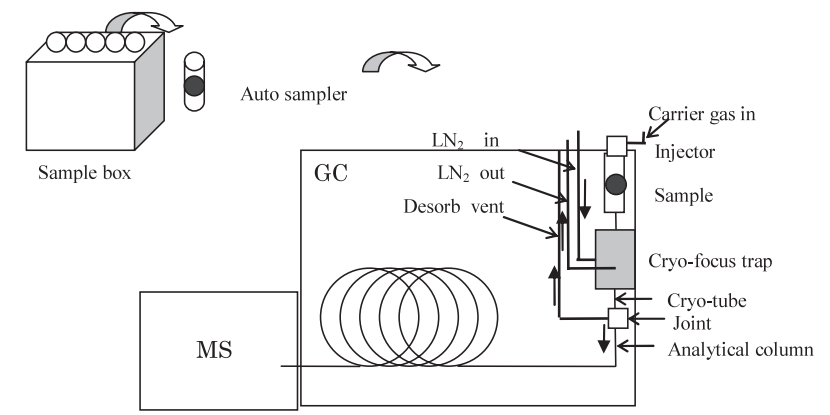

Fig. 2. Schematic Diagram of the TD-GC/MS System

TD-GC/MS — The PAHs were analyzed with a T-Dex II TD system (GL Sciences Inc., Tokyo, Japan) installed on a Varian GC-3800 GC with a Varian 300-TQMS (Varian Inc., Lake Forest, CA, U.S.A.). Varian MS Workstation software (ver. 6.9) was used for raw data analysis. The TD instrument was equipped with a TD auto sampler system. The TD tube (Pyrex, $89 \mathrm{~mm}$ length, $4 \mathrm{~mm}$ Internal Diameter (I.D.), $6 \mathrm{~mm}$ Outside Diameter) was automatically placed in the TD area under the injection port of the GC. We did not use glass wool to hold the sample in the TD tube. The cryogenic-focus trap system was located below the TD area in the GC oven and was cooled initially with $-100^{\circ} \mathrm{C}$ liquid nitrogen. A schematic diagram of the TD-GC/MS system is shown in Fig. 2. Use of the cryogenicfocus system permitted effective separation and thus increased peak height. For reuse, the TD tubes were baked for $1 \mathrm{hr}$ at $400^{\circ} \mathrm{C}$ under flowing helium gas at a flow rate of $100 \mathrm{ml} / \mathrm{min}$. TD analysis of each sample was performed automatically by means of the T-Dex II programming. We selected $350^{\circ} \mathrm{C}$ as the TD temperature because this temperature does not favor pyrolysis and is effective for desorption of PAHs. Ho and $\mathrm{Yu}^{9)}$ also reported that the best TD temperature is $>300^{\circ} \mathrm{C}$. Fushimi et al. ${ }^{10)}$ showed that desorption is incomplete at temperatures of $>250^{\circ} \mathrm{C}$ and that considerable pyrolysis occurs at temperatures of $>550^{\circ} \mathrm{C}$. These authors also showed that the peak abundances for ramped desorption to $350^{\circ} \mathrm{C}$ and to $450^{\circ} \mathrm{C}$ were equivalent.

In the first step (initial mode), the outside of the TD tube was purged from bottom to top with helium gas at a flow rate of $25 \mathrm{ml} / \mathrm{min}$. In the second step (TD mode), the TD tube was heated from $45^{\circ} \mathrm{C}$ (held for $1 \mathrm{~min}$ ) to $350^{\circ} \mathrm{C}$ (held for $10 \mathrm{~min}$ ) at a rate of $5^{\circ} \mathrm{C} / \mathrm{s}$ with helium gas at a flow rate of $40 \mathrm{ml} / \mathrm{min}$ (in split mode; $5 \mathrm{ml} / \mathrm{min}$ for sample and $35 \mathrm{ml} / \mathrm{min}$ for split). 
Desorbed compounds were collected in the cryogenic-focus trap at $-100^{\circ} \mathrm{C}$ with liquid nitrogen in a cryotube $(0.53 \mathrm{~mm}$ I.D., inert fused silica capillary column). Trapped compounds were reheated from $-100^{\circ} \mathrm{C}$ (held for $1 \mathrm{~min}$ ) to $300^{\circ} \mathrm{C}$ (held for $10 \mathrm{~min}$ ) at a rate of $50^{\circ} \mathrm{C} / \mathrm{s}$ and then were sent to an analytical capillary column.

The $\mathrm{GC}$ was heated from $60^{\circ} \mathrm{C}$ (held for $3 \mathrm{~min}$ ) to $200^{\circ} \mathrm{C}$ at a rate of $15^{\circ} \mathrm{C} / \mathrm{min}$ and then to $325^{\circ} \mathrm{C}$ (held for $10 \mathrm{~min}$ ) at a rate of $5^{\circ} \mathrm{C} / \mathrm{min}$. The compounds were separated on a Factor Four capillary column (model VF- $5 \mathrm{~ms} ; 30 \mathrm{~m} \times 0.25 \mathrm{~mm}$ i.d., $0.25 \mu \mathrm{m}$ film thickness, lowest guaranteed bleed specification temperature $325^{\circ} \mathrm{C}$; Varian Inc.). The helium carrier gas was supplied at $1.3 \mathrm{ml} / \mathrm{min}$ for GC/MS. SIM mode was used for quantitative analysis in this study. The GC injector, ion-source, and transfer-line temperatures were 270, 230, and $280^{\circ} \mathrm{C}$, respectively.

EC and OC Analysis - EC and OC in the DEP on the quartz-fiber filters were analyzed with a thermal/optical carbon analyzer (DRI model 2001 Carbon Analyzer; Desert Research Institute, Las Vegas, NV, U.S.A. $)^{14)}$ with the IMPROVE thermal/optical reflectance protocol. A sample $\left(0.503 \mathrm{~cm}^{2}\right.$ area; $8 \mathrm{~mm}$ diameter) punched from a quartz-fiber filter was heated at 120 (OC1), 250 (OC2), 450 (OC3), and $550(\mathrm{OC} 4){ }^{\circ} \mathrm{C}$ in a helium atmosphere and at 550 (EC1), 700 (EC2), and $800(\mathrm{EC} 3)^{\circ} \mathrm{C}$ in an oxidizing atmosphere (2\% oxygen, $98 \%$ helium). ${ }^{19)}$ We calculated PAH/OC and PAH/EC under various test conditions. OC and EC were calculated with a $\mu \mathrm{gC}$ base.

\section{RESULTS AND DISCUSSION}

\section{Number Concentrations of DEP}

The particle size distributions of DEP in the engine-out exhaust gas, in the exhaust gas of the engine equipped with the DOC alone, and with both devices are shown in Figs. 3 and 4 for the ETC and the ESC, respectively. For both cycles, bimodal distributions were observed; a large peak with a modal diameter of around $50 \mathrm{~nm}$ and a small peak with a modal diameter of around $10 \mathrm{~nm}$ were observed. For both the ETC and ESC, the number concentrations of DEP were almost the same for the engineout exhaust and the exhaust of the engine equipped with the DOC alone. The DOC oxidizes CO and hydrocarbons but does not remove diesel soot particles. In contrast, the number concentrations of DEP

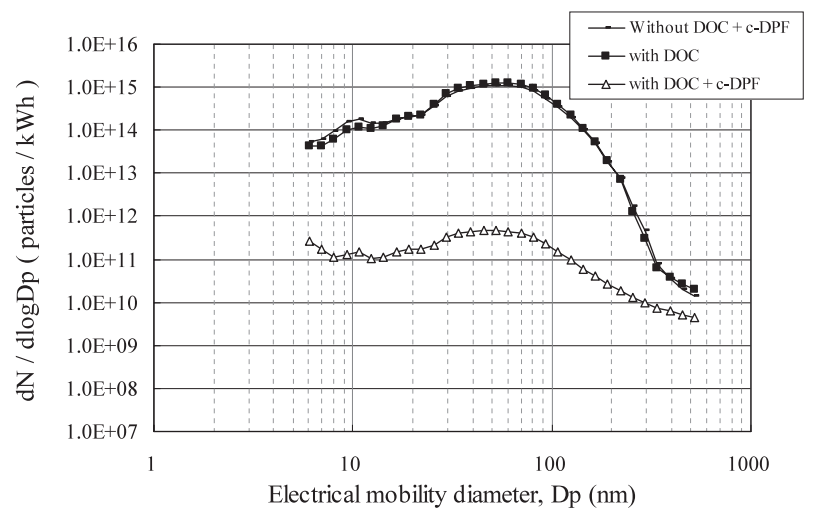

Fig. 3. Particle Size Distribution of DEP in the ETC, Obtained by means of EEPS

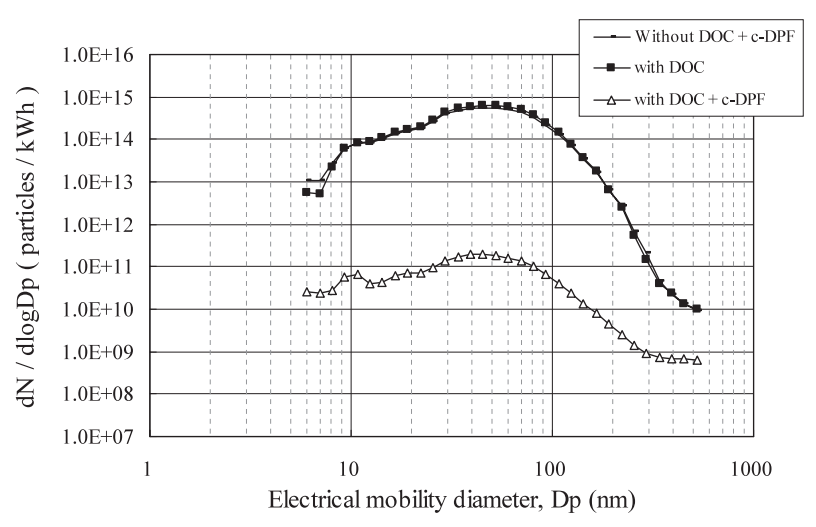

Fig. 4. Particle Size Distribution of DEP in the ESC, Obtained by means of EEPS

were dramatically decreased (> 99.9\%) when both aftertreatment devices were used. This represents the effectiveness of the c-DPF. The decrease rate of the number concentrations did not depend on the diameter of particles between $5.6 \mathrm{~nm}$ and $200 \mathrm{~nm}$ in either cycle. It was shown that the c-DPF can decrease nano and ultrafine particles, and that has high performance ability for DEP reduction.

\section{TD-GC/MS}

The correlation coefficients $\left(R^{2}\right)$ of calibration curves measured at six levels between 0.007 and $2.91 \mathrm{ng}$ were in the range of $0.964-0.997$, indicating good linearity. The limits of detection and quantification for the 8 PAHs revealed remarkably low values that were $0.002-0.167 \mathrm{ng}$ and $0.008-0.557 \mathrm{ng}$, respectively.

Effectiveness of the Latest Aftertreatment Devices for Reduction of PAH Emissions

DEP were collected on the quartz filter un- 


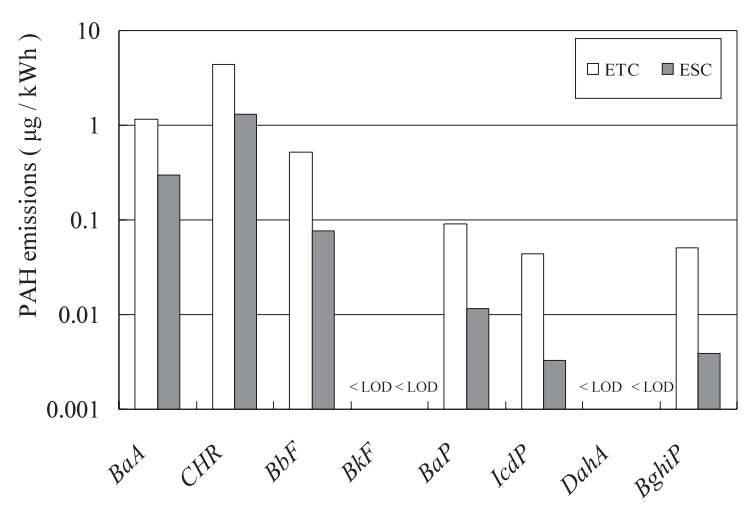

Fig. 5. PAH Emissions in the Engine-out Exhaust Gas in the ETC and the ESC

der engine-out conditions, and these amounted to $3.37 \mathrm{mg}$ in the ETC and $2.2 \mathrm{mg}$ in the ESC. With aftertreatment (DOC $+\mathrm{c}-\mathrm{DPF})$, the quantity of DEP collected was $0.20 \mathrm{mg}$ in the ETC and $0.16 \mathrm{mg}$ in the ESC. We calculated the weight of DEP on the punched $10 \mathrm{~mm}$ diameter filter. From these, $94 \mu \mathrm{g}$ was collected from the ETC and $61 \mu \mathrm{g}$ in the ESC under engine-out conditions, and $5.5 \mu \mathrm{g}$ in the ETC and $4.4 \mu \mathrm{g}$ in the ESC under the aftertreatment $(\mathrm{DOC}+\mathrm{c}-\mathrm{DPF})$ equipped conditions. PAH emissions in the engine-out exhaust gases are shown in Fig. 5 from the ETC and the ESC. The PAH emissions in the ETC were higher than the ESC, but this is thought to be due to the greater mass of DEP collected during the ETC than the ESC. On the whole, the engine load of the ETC is lower than the ESC (Fig. 1). Additionally, exhaust temperature in the ETC is lower than the ESC with and without aftertreatment devices. In particular, at the start of cycle, the inlet temperature of DOC in the ETC is about $100^{\circ} \mathrm{C}$, that is lower than active temperature of the catalyst. Therefore, PAH emissions in the ETC is higher than the ESC, because PAH are not oxidized at the start of the ETC, and emit to the engine exhaust.

Total emissions of the eight PAHs following aftertreatment with DOC + c-DPF in the ETC and ESC were remarkably decreased compared to the emissions in the engine-out exhaust gases (Figs. 6-9); the total decrease rates were $98.4 \%$ in the ETC and $97.7 \%$ in the ESC. For the ETC, the decrease rates for the individual PAHs were as follows: $\mathrm{B} a \mathrm{~A}$ 95.7\%, CHR 99.1\%, $\mathrm{B} b \mathrm{~F} 98.8 \%$, $\mathrm{B} a \mathrm{P} 93.2 \%, \mathrm{I} c d \mathrm{P}>99.8 \%$, and $\mathrm{B} g h i \mathrm{P}>99.9 \%$. The levels of $\mathrm{B} k \mathrm{~F}$ and $\mathrm{D} a h \mathrm{~A}$ were below the LOD in the engine-out exhaust, and these compounds were not detected when the engine was

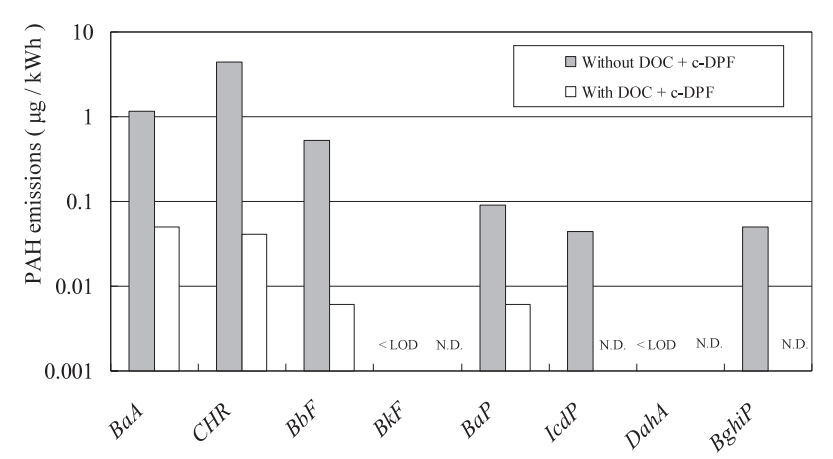

Fig. 6. PAH Emissions with and without DOC $+c-D P F$ in the ETC

N.D., not detected.

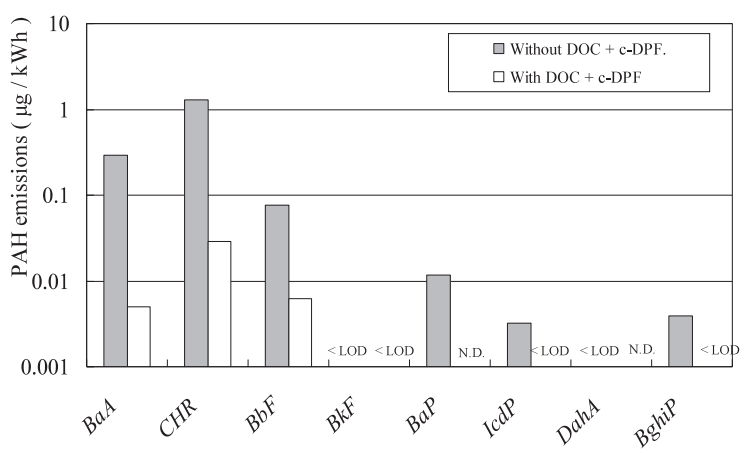

Fig. 7. $\mathrm{PAH}$ Emissions with and without $\mathrm{DOC}+\mathrm{c}-\mathrm{DPF}$ in the ESC

N.D., not detected.

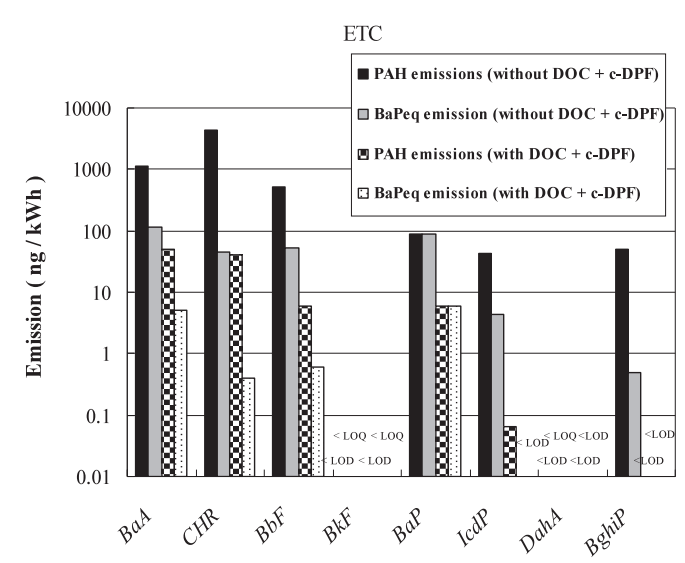

Fig. 8. Comparison of Distributions of PAH and $\mathrm{B} a \mathrm{Peq}$ Emissions with and without Aftertreatment in the ETC

equipped with the aftertreatment devices. For the $\mathrm{ESC}$, the decrease rates were as follows: $\mathrm{B} a \mathrm{~A}$ 98.3\%, CHR 97.8\%, B bF 91.9\%, B $a \mathrm{P}>99.9 \%$, $\mathrm{I} c d \mathrm{P} 73.3 \%$, and $\mathrm{B} g h i \mathrm{P} 77.8 \%$. The level of $\mathrm{B} k \mathrm{~F}$ was $<$ LOD both with and without the aftertreatment devices, and the level of DahA was $<$ LOD in the engine-out exhaust, and the compound was not detected when the engine was 


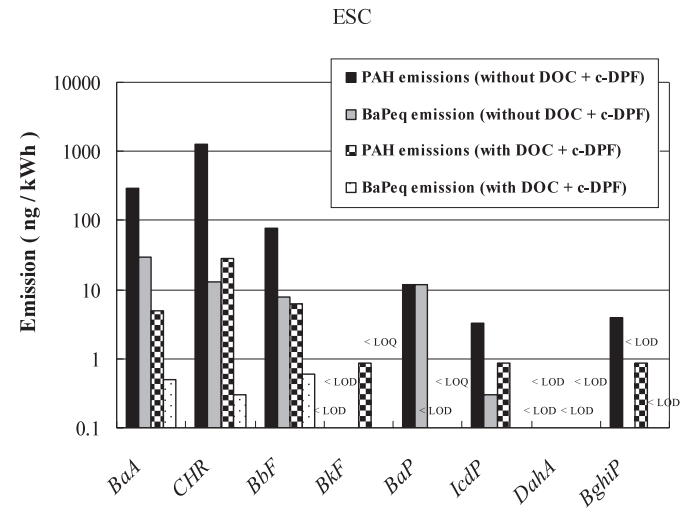

Fig. 9. Comparison of Distributions of PAH and $\mathrm{B} a$ Peq Emissions with and without Aftertreatment in the ESC

equipped with the aftertreatment devices. Therefore, the reduction rate for both cycles was the same, but it was slightly higher for the ETC than for the ESC.

\section{Carbonaceous Emissions, PAH/OC and PAH/EC Ratios under Various Test Conditions}

The EC and OC emissions are shown in Fig. 10. When the engine was equipped with the aftertreatment devices, the decrease rates of EC in the DEP were $99.6 \%$ in the ETC and $99.7 \%$ in the ESC, and the decrease rates of OC in the DEP were $72.1 \%$ in the ETC and $78.2 \%$ in the ESC. The decrease rates in EC in the DEP for both cycles were significantly higher than those for OC. We thought that the large decrease rate for EC was due to the reduction of diesel soot particles by the c-DPF, because the DOC oxidizes $\mathrm{CO}$ and hydrocarbons but does not decrease diesel soot particles. Therefore, these results indicated that the aftertreatment devices have high effectiveness for removal of EC but it is thought that $\mathrm{OC}$ is not collected completely when the aftertreatment devices fail to reach the active temperature at the start of the ETC and ESC.

The PAH/OC ratios over the ETC and ESC are shown in Fig. 11. All the ratios fell in a range from 1 $\times 10^{-2}$ to $1 \times 10^{-4}$ in the engine-out exhaust. When the engine was equipped with the aftertreatment devices, all the ratios fell in a range from $1 \times 10^{-3}$ to 1 $\times 10^{-4}$. Except in the case of $\mathrm{B} k \mathrm{~F}$ and $\mathrm{B} g h i \mathrm{P}$ in the $\mathrm{ESC}$, the $\mathrm{PAH} / \mathrm{OC}$ ratios decreased by nearly one order of magnitude under conditions where the aftertreatment devices used. The PAH/EC ratios in the ETC and ESC are shown in Fig. 12. All ratios fell in a range from $1 \times 10^{-2}$ to $1 \times 10^{-4}$ in the engineout exhaust. When the aftertreatment devices were attached, all the $\mathrm{PAH} / \mathrm{EC}$ ratios fell in a range from
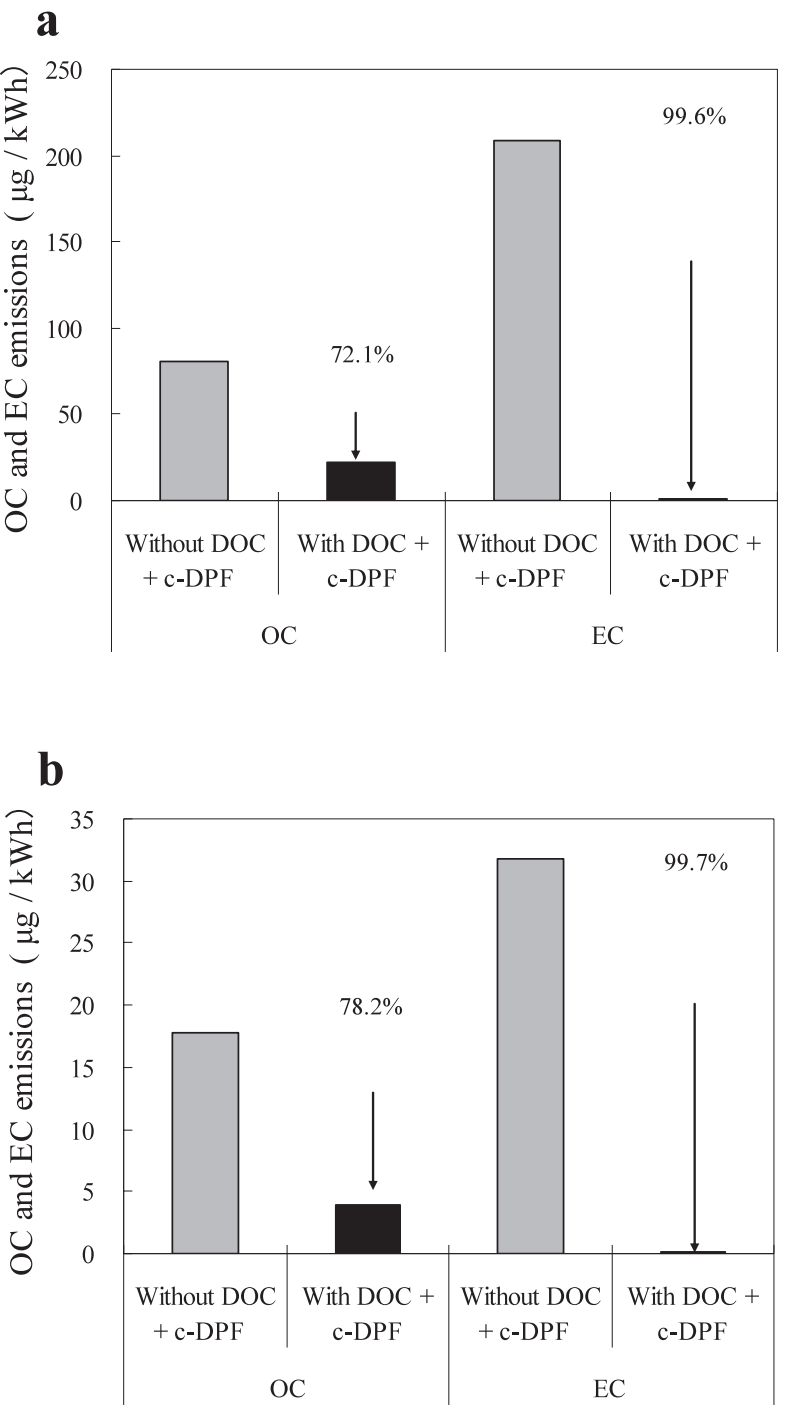

Fig. 10. OC and EC Emissions in DEP in the ETC (a) and in the ESC (b)

$1 \times 10^{-1}$ to $1 \times 10^{-4}$, the ratios were greater than in the engine-out condition. Because the EC mass had decreased due to the aftertreatment devices, it was assumed that the PAH/EC ratio had increased.

\section{Effectiveness of the Latest Aftertreatment De- vices for Reduction of Toxicity}

From the view point of health effects, we calculated the total reduction rate of toxicity for the DEP emitted from a diesel engine fitted with the latest aftertreatment devices. Yang et al. (2005) ${ }^{15)}$ calculated the $\mathrm{B} a$ Peq emission factor for individual PAHs by multiplying the emission factor with the corresponding TEF values. The results are shown in Tables 3 and 4, and Figs. 8 and 9. The total reduction rate of $\mathrm{B} a \mathrm{Peq}$ emissions under ETC and ESC when the aftertreatment devices were fitted was $96.1 \%$ 
Table 3. Comparison of $\mathrm{B} a$ Peqs with and without Aftertreatment Devices for the ETC

\begin{tabular}{lccc}
\hline \hline PAH & TEF $^{a)}$ & $\begin{array}{c}\text { BaPeq emissions without } \\
\text { DOC +c-DPF (ng/kWh) }\end{array}$ & $\begin{array}{c}\text { BaPeq emissions with } \\
\text { DOC + c-DPF (ng/kWh) }\end{array}$ \\
\hline $\mathrm{B} a \mathrm{~A}$ & 0.10 & 115.1 & 5.0 \\
$\mathrm{CHR}$ & 0.01 & 44.2 & 0.4 \\
$\mathrm{~B} b \mathrm{~F}$ & 0.10 & 52.4 & 0.6 \\
$\mathrm{~B} k \mathrm{~F}$ & 0.10 & $<\mathrm{LOD}$ & $<\mathrm{LOD}$ \\
$\mathrm{B} a \mathrm{P}$ & 1.00 & 90.1 & 6.1 \\
$\mathrm{I} c d \mathrm{P}$ & 0.10 & 4.4 & $<\mathrm{LOD}$ \\
$\mathrm{D} a h \mathrm{~A}$ & 0.10 & $<\mathrm{LOD}$ & $<$ LOD \\
$\mathrm{B} g h i \mathrm{P}$ & 0.01 & 0.5 & $<$ LOD \\
Total & - & 306.6 & 12.1 \\
\hline Decrease rate for total & - & - & 96.1 \\
$\mathrm{~B} a$ Peq emissions $(\%)$ & & & \\
\hline
\end{tabular}

a) Values reported by Yang et al. (2005). ${ }^{15)}$

Table 4. Comparison of $\mathrm{B} a$ Peqs with and without Aftertreatment Devices for the ESC

\begin{tabular}{lccc}
\hline \hline PAH & TEF $^{a)}$ & $\begin{array}{c}\text { BaPeq emissions without } \\
\text { DOC + c-DPF (ng/kWh) }\end{array}$ & $\begin{array}{c}\text { BaPeq emissions with } \\
\text { DOC + c-DPF (ng/kWh) }\end{array}$ \\
\hline $\mathrm{B} a \mathrm{~A}$ & 0.10 & 29.5 & 0.5 \\
$\mathrm{CHR}$ & 0.01 & 13.0 & 0.3 \\
$\mathrm{~B} b \mathrm{~F}$ & 0.10 & 7.7 & 0.6 \\
$\mathrm{~B} k \mathrm{~F}$ & 0.10 & $<\mathrm{LOD}$ & 0.1 \\
$\mathrm{~B} a \mathrm{P}$ & 1.00 & 11.7 & $<\mathrm{LOD}$ \\
$\mathrm{I} c d \mathrm{P}$ & 0.10 & 0.3 & 0.1 \\
$\mathrm{D} a h \mathrm{~A}$ & 0.10 & $<\mathrm{LOD}$ & $<\mathrm{LOD}$ \\
$\mathrm{B} g h i \mathrm{P}$ & 0.01 & $<\mathrm{LOD}$ & $<\mathrm{LOD}$ \\
Total & - & 62.2 & 1.6 \\
\hline Decrease rate for total & - & - & 97.4 \\
$\mathrm{~B} a$ Peq emissions $(\%)$ & & & \\
\hline
\end{tabular}

a) Values reported by Yang et al. (2005). ${ }^{15)}$

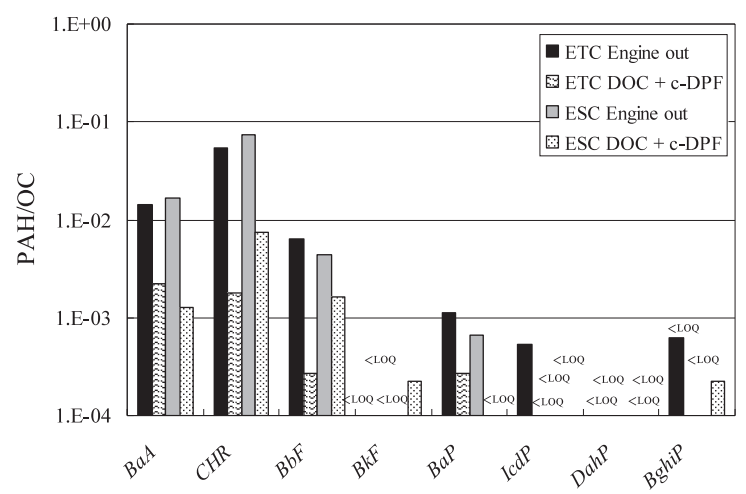

Fig. 11. Ratio of PAH to OC under Various Test Conditions

and $97.4 \%$, respectively.

Thus, the reduction rates for both cycles were almost similar, but the ESC rate was slightly higher than for the ETC. This result shows that the presence of the aftertreatment devices dramatically decreased the toxicity of diesel engine exhaust.

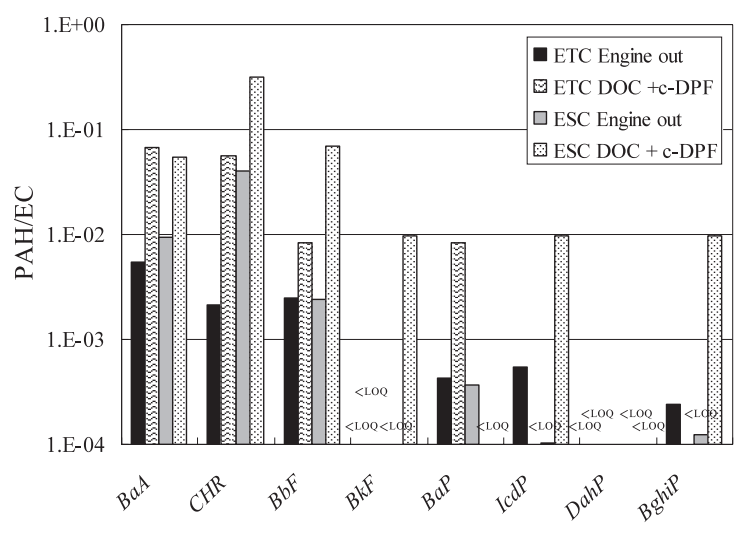

Fig. 12. Ratio of PAH to EC under Various Test Conditions

\section{Comparison of the Distributions of PAH and BaPeq Emissions}

Figures 8 and 9 show the comparison of the distributions and trends of PAH emissions and $\mathrm{B} a \mathrm{Peq}$ emissions. Under two different test cycles, the dis- 
tributions and trends were very similar with and without the aftertreatment devices.

In conclusion, we have evaluated the reduction efficiency and distribution of PAH emissions and toxicity from a diesel engine equipped with the latest combination of DOC + c-DPF using TDGC/MS. We analyzed eight target PAHs in very low masses of DEP and determined the quantities of the target PAHs in DEP obtained from the engine operated under representative conditions of the ETC and the ESC. When the aftertreatment devices were fitted to the engine, the overall number concentrations of DEP, total emissions of the eight PAHs and the quantity of EC in the DEP were dramatically decreased to $>99 \%$, $>97 \%$ and $>99 \%$, respectively. However the decrease rate of OC was lower than EC (> 72\%). The decrease rate of number concentrations did not depend on diameter of particles between $5.6 \mathrm{~nm}$ and $200 \mathrm{~nm}$. It was shown that the c-DPF decreases nano and ultrafine particles.

The $\mathrm{B} a$ Peq emissions of the eight PAHs were also evaluated using TEF to determine the reduction in carcinogenic potency afforded by the aftertreatment devices, and this analysis revealed that the decrease rate was very high $(>95 \%)$. The decrease rate for the ESC was slightly higher than for the ETC.

We demonstrated that number concentrations of DEP, PAH emissions, the quantity of EC and $\mathrm{B} a \mathrm{Peq}$ emissions decreased similarly and significantly with the latest aftertreatment devices. The effectiveness of the DOC + c-DPF combination was fully demonstrated by means of the TD-GC/MS method and showed that the total emissions of PAHs, number concentrations and the quantity of EC in DEP decreased by two orders of magnitude.

Acknowledgements This work was supported in part by a grant-in-aid from the Science Research Fund of the Ministry of Education, Culture, Sports, Science and Technology (MEXT) of Japan (No. 19310045).

\section{REFERENCES}

1) Boström, C. E., Gerde, P., Hanberg, A., Jernström, B., Johansson, C., Kyrklund, T., Rannug, A., Törnqvist, M., Victorin, K. and Westerholm, R. (2002) Cancer risk assessment, indicators, and guidelines for polycyclic aromatic hydrocarbons in the ambient air. Environ. Health
Perspect., 110, 451-488.

2) Lin, C. C., Chen, S. J., Huang, K. L., Lee, W. J., Lin, W. Y., Tsai, J. H. and Chaung, H. C. (2008) PAHs, PAH-induced carcinogenic potency, and particle-extract-induced cytotoxicity of trafficrelated nano/ultrafine particles. Environ. Sci. Technol., 42, 4229-4235.

3) US Environmental Protection Agency (2002) Health assessment document for diesel engine exhaust. EPA's office of Research and Development (ORD), Washington, DC, EPA/600/8-90/057F.

4) Poster, D., Schantz, M. M., Sander, L. C. and Wise, S. A. (2006) Analysis of polycyclic aromatic hydrocarbons (PAHs) in environmental samples: a critical review of gas chromatographic (GC) methods. Anal. Bioanal. Chem., 386, 859-881.

5) Neusüss, C., Pelzing, M., Plewka, A. and Herrmann, H. (2000) A new analytical approach for sizeresolved speciation of organic compounds in atmospheric aerosol particles: Methods and first results. J. Geophys. Res., 105, 4513-4527.

6) Waterman, D., Horsfield, B., Leistner, F., Hall, K. and Smith, S. (2000) Quantification of polycyclic aromatic hydrocarbons in the NIST standard reference material (SRM1649A) urban dust using thermal desorption GC/MS. Anal. Chem., 72, 35633567.

7) Falkovich, A. H. and Rudich, Y. (2001) Analysis of semivolatile organic compounds in atmospheric aerosols by direct sample introduction thermal desorption GC/MS. Environ. Sci. Technol., 35, 23262333.

8) Hays, M. D., Smith, N. D., Kinsey, J., Dong, Y. and Kariher, P. (2003) Polycyclic aromatic hydrocarbon size distributions in aerosols from appliances of residential wood combustion as determined by direct thermal desorption-GC/MS. J. Aerosol Sci., 34, 1061-1084.

9) Ho, S. S. H. and Yu, J. Z. (2004) Injection port thermal desorption and subsequent gas chromatography-mass spectrometric analysis of polycyclic aromatic hydrocarbons and n-alkanes in atmospheric aerosol samples. J. Chromatogr. A, 1059, 121-129.

10) Fushimi, A., Tanabe, K., Hasegawa, S. and Kobayashi, S. (2007) Investigation of characterization method for nanoparticles in roadside atmosphere by thermal desorption-gas chromatography/mass spectrometry using a pyrolyzer. Sci. Total Environ., 386, 83-92.

11) Hays, M. D. and Lavrich, R. J. (2007) Developments in direct thermal extraction gas chromatographymass spectrometry of fine aerosols. Trends in Analytical Chemistry, 26, 88-102. 
12) Iwakiri, Y., Kanno, H. and Koyama, H. (2007) A study of an analysis method for trace substances in vehicle exhaust gas. Society of Automotrve Engineers Paper, 2007-01-0306.

13) Lavrich, R. J. and Hays, M. D. (2007) Validation studies of thermal extraction-GC/MS applied to source emissions aerosols. 1. Semivolatile analytenonvolatile matrix interactions. Anal. Chem., 79, 3635-3645.

14) Chow, J. C., Watson, J. G., Pritchett, L. C., Pierson, W. R., Frazier, C. A. and Purcell, R. G. (1993) The DRI thermal/optical reflectance carbon analysis system: description, evaluation and applications in US air quality studies. Atmos. Environ., 27A, 1185-1201.

15) Yang, H. H., Chien, S. M., Chao, M. R. and Lin, C. C. (2005) Particle size distribution of polycyclic aromatic hydrocarbons in motorcycle exhaust emissions. J. Hazard. Mater., B125, 154-159.

16) US Environmental Protection Agency (1999) Compendium of methods for determination of toxic or- ganic compounds in ambient air second edition. Compendium method TO-13A. EPA's office of Research and Development (ORD), Washington, DC, EPA/625/R-96/010b.

17) Khalek, I. A., Ullman, T. L., Shimpi, S. A., Jackson, C. C., Dharmawardhana, B., Silvis, W. M., Kreft, N., Harvey, R. N., Munday, D., Yamaguchi, Y., Graze, R., Smitherman, J. and Adkins, J. (2002) Performance of partial flow sampling systems relative to full flow CVS for determination of particulate emissions under steady-state and transient diesel engine operation. SAE Paper, 2002-01-1718.

18) Ayala, A., Chernich, D. J., Huai, T., Johnson, K. C. and Miller, W. (2005) Emission correlation between a partial-flow diluter and the full-flow constant volume sampler (CVS) for a heavy-duty vehicle under steady-state operation. SAE Paper, 2005-01-3798.

19) Chow, J. C., Watson, J. G., Crow, D., Lowenthal, D. H. and Merrifield, T. (2001) Comparison of IMPROVE and NIOSH carbon measurements. Aerosol Sci. Technol., 34, 23-34. 